\title{
Rotavirus vaccines and intussusception: A little alarm bell perhaps?
}

\author{
Sri Lanka Journal of Child Health, 2014; 43(1): 1-2
}

(Key words: Rotavirus vaccine; intussusception)

Diarrhoeal diseases are a major cause of childhood morbidity and mortality the world over. This is particularly true of the developing world ${ }^{1}$. A considerable proportion of diarrhoea morbidity is due to rotavirus infection ${ }^{2}$. Treatment consists of rehydration and symptomatic measures. There are no specific anti-viral drugs available to treat rotaviruses and the search for a vaccine to prevent the disease has been promoted for a number of decades. Several vaccines have been evaluated and three of them have been licensed after testing for their efficacy and safety.

The first such vaccine to be introduced, in the latter part of the $1990 \mathrm{~s}$, was a tetravalent rotavirus vaccine (RotaShield, Wyeth Lederle). However, the vaccine was withdrawn voluntarily by the manufacturers, within a short period after being licensed, due to an increased occurrence of intussusceptions following administration of the vaccine. The documented risk of intussusception was estimated to be around 1 to 2 cases per 10,000 recipients of the vaccine ${ }^{3}$.

There were other vaccines that were being tested from that time onwards. In 2006, following rigorous testing procedures, a pentavalent rotavirus vaccine (RV5; RotaTeq, Merck) was introduced and in 2008, another monovalent human rotavirus vaccine (RV1; Rotarix, GlaxoSmithKline) was provided for clinical use. These had been evaluated in trials involving more than 60,000 infants, with sufficient power to facilitate detection of an increased risk of intussusception and were deemed to be safe. Two important studies published in the New England Journal of Medicine ${ }^{4,5}$ confirmed their efficacy and safety. Since then, the two vaccines have gone into general usage and the burden of the disease and severity of diarrhoeal illnesses have been significantly and substantially reduced in several countries by the use of these vaccines $\mathrm{s}^{6,7,8}$. The vaccines are used in the National Immunisation Programmes of several countries.

These vaccines have been subjected to postlicensure monitoring from the time of introduction and meticulous data has been collected over the last few years. Two papers published in the New England Journal of Medicine ${ }^{9,10}$ have now sounded an early alarm bell regarding the occurrence of intususception following administration of both RotaTeq and Rotarix vaccines.
The first paper $^{9}$ concluded that using two complementary analytic designs, an association between the pentavalent vaccine (RV5; RotaTeq, Merck) and intussusceptions has been established. The risk was at its peak in a three to seven day period following the first dose. The estimated risk was assessed to be 1.5 per 100,000 recipients of the first dose. This risk was noted to be about one tenth of the risk associated with the earlier RotaShield vaccine. The authors also stated that that the risk of intussusception should be balanced against the documented benefits of the vaccine.

The second paper ${ }^{10}$ using sequential monitoring analyses, documented an increased risk of intussusception within 7 days after the administration of any dose of the monovalent rotavirus vaccine (RV1; Rotarix, GlaxoSmithKline). However, the authors also stated that although an increased risk of intussusception associated with monovalent rotavirus vaccination was noted, the welldocumented benefits of rotavirus vaccination need to be considered. They also confirmed that since the start of the U.S. rotavirus vaccination program, large declines in rotavirus disease and associated hospitalizations have occurred among U.S. infants and that the benefits of rotavirus vaccination in infants have been found to outweigh possible small risks of intussusception.

An editorial in the same issue of the New England Journal of Medicine ${ }^{11}$ states that "the differences between the studies are marginal, and it appears that both vaccines cause intussusception at low rates; therefore, small variations in case detection and in confirmation of vaccination status, as well as chance alone, can introduce considerable uncertainty into the analysis". The editorial further states that "Many questions remain to be resolved: Is the risk of intussusception similar with the two vaccines? What is the mechanism for the event? Can we identify a subgroup of infants who may be at increased risk? And will the findings of the risk of intussusception from high-income and middleincome countries extend to low-income countries, where these vaccines are known to be less efficacious and, thus, may be associated with a lower risk?" The editorial goes on to say that "despite lower efficacy in low-income countries, the public health benefits of rotavirus vaccines in these settings, where the vast majority of deaths 
from rotavirus occur, are likely to be substantial and outweigh a small risk of intussusceptions".

As for the local scenario in Sri Lanka, childhood deaths from diarrhoeal diseases are extremely low and perhaps almost insignificant. However, there is a significant disease burden with diarrhoeal diseases in the country leading to the need for treatment in the public sector as well as in private management facilities. This phenomenon has considerable economic implications as well, resulting from direct and indirect costs of the disease. Since of late, rotavirus vaccines are being increasingly used in the fee-levying private health sector of Sri Lanka. The vaccines have not been introduced into the National Expanded Programme of Immunisation of the Ministry of Health, the venture responsible for providing free vaccinations for the vast majority of children in the country.

Health professionals need to look carefully at the emerging evidence for an association of intussusceptions with the currently available rotavirus vaccines. However, it is imperative to point out that, in view of the documented benefits of the rotavirus vaccine, there is no reason to withhold the administration of the vaccine in the private health sector of the country. Yet for all that, in view of recent developments regarding the documented small increase in the incidence of intussusceptions following these vaccines, it is best to consider that sharp-eyed and sustained vigilance is perhaps the need of the hour.

\section{References}

1. Parashar UD, Bresee JS, Glass RI. The global burden of diarrhoeal disease in children. Available from: http://dx.doi.org/10.1590/S0042968620030004 00003 Accessed 23-01-2014

2. Parashar UD, Hummelman EG, Bresee JS, Miller MA, Glass RI. Global illness and deaths caused by rotavirus disease in children. Emerging Infectious Diseases 2003; 9(5):565-72. http://dx.doi.org/10.3201/eid0905.020562

3. Murphy TV, Gargiullo PM, Massoudi MS, et al. Intussusception among infants given an oral rotavirus vaccine. New England Journal of Medicine 2001; 344:564-72.

http://dx.doi.org/10.1056/NEJM200102223440804

4. Vesikari T, Matson DO, Dennehy P, et al. Safety and efficacy of a pentavalent humanbovine (WC3) reassortant rotavirus vaccine. New England Journal of Medicine 2006; 354:23-33.

http://dx.doi.org/10.1056/NEJMoa052664
5. Ruiz-Palacios GM, Perez-Schael I, Velazquez FR, et al. Safety and efficacy of an attenuated vaccine against severe rotavirus gastroenteritis. New England Journal of Medicine 2006; 354:11-22.

http://dx.doi.org/10.1056/NEJMoa052434

6. Patel MM, Steele D, Gentsch JR, Wecker J, Glass RI, Parashar UD. Real-world impact of rotavirus vaccination Pediatric Infectious Diseases Journal 2011; 30: Suppl: S1-S5. http://dx.doi.org/10.1097/INF.0b013e3181fefa1f

7. Tate JE, Mutuc JD, Panozzo CA, et al. Sustained decline in rotavirus detections in the United States following the introduction of rotavirus vaccine in 2006. Pediatric Infectious Diseases Journal 2011; 30: Suppl: S30-S34. http://dx.doi.org/10.1097/INF.0b013e3181ffe3eb

8. Gastanaduy PA, Sanchez-Uribe E, EsparzaAguilar M, et al. Effect of rotavirus vaccine on diarrhoea mortality in different socioeconomic regions of Mexico Pediatrics 2013; 131:e1115-e1120. http://dx.doi.org/10.1542/peds.2012-2797

9. Yih WK, Lieu TA, Kulldorff $M$, et al. Intussusception risk after rotavirus vaccination in U.S. infants. New England Journal of Medicine (on line first) $14^{\text {th }}$ January 2014 Available from: http://www.nejm.org/doi/full/10.1056/NEJMoa 1303164 ?query $=\mathrm{TOC} \# \mathrm{t}=$ article. http://dx.doi.org/10.1056/NEJMoa1303164

10. Weintraub ES, Baggs J, Duffy J, et al. Risk of intussusception after monovalent rotavirus vaccination New England Journal of Medicine (on line first) $14^{\text {th }}$ January 2014. Available from:

http://www.nejm.org/doi/full/10.1056/NEJMoa 1311738 ?query $=$ TOC $\# \mathrm{t}=$ article http://dx.doi.org/10.1056/NEJMoa1311738

11. Glass RI, Parashar UD. Rotavirus vaccines Balancing intussusception risks and health benefits New England Journal of Medicine (Editorial - on line first) $14^{\text {th }}$ January 2014. Available from: http://www.nejm.org/doi/full/10.1056/NEJMe1 315836 ?query $=$ TOC. http://dx.doi.org/10.1056/NEJMe1315836

\section{B J C Perera}

Joint Editor 